\title{
Aplicação de Mineração de Dados para o Auxílio da Tomada de Decisão em Gestão de Pessoas
}

\author{
Samuel Brati Favarin \\ Laboratório de Inteligência Aplicada \\ Universidade do vale do Itajaí \\ Itajaí, Santa Catarina, Brasil \\ favarin@edu.univali.br
}

\author{
Rafael Ballottin Martins \\ Laboratório de Inteligência Aplicada \\ Universidade do vale do Itajaí \\ Itajaí, Santa Catarina, Brasil \\ ballottin@univali.br
}

\begin{abstract}
People are the foundation of organizations. For companies remain competitive, they need to develop and maintain their human resources. Professionals of the area, must rely on data to make their decisions, otherwise, it can generate bad decisions, taken only by intuition or experience. In this context, this project aimed to help the future decision making process made by human resource specialists of a People Management Software Company using the KDD process to generate new knowledge. In the data mining stage were used The Decision Tree, Neural Network, APRIORI and KMeans algorithms, generating patterns to be analysed with human resource specialists. Preliminary results demonstrate that it is possible to observe standards that classify employees as highly engaged, engaged, neutral and disengaged.
\end{abstract}

\section{KEY WORDS}

Data Mining, Gestão de Pessoas, People Analytics

\section{INTRODUÇÃO}

A área de gestão de pessoas é crucial para o desenvolvimento das organizações. O gestor de pessoas é responsável por manter, recrutar, recompensar e desenvolver os colaboradores. Nesse contexto, decisões tomadas sem embasamento em conhecimentos providos por dados, podem causar problemas para as organizações e para os colaboradores [1].

Em busca de promover melhores resultados para as empresas, o investimento em melhorias no engajamento dos colaboradores pode impactar no desempenho, performance e produtividade dos mesmos. O colaborador quando engajado, possui de maneira genuína a vontade de trabalhar e promover a empresa [2][3].

Identificar padrões em colaboradores desengajados, é de extrema importância para que as organizações consigam lhes oferecer melhorias nas condições de trabalho, de maneira que seu engajamento cresça e sua produtividade e desenvolvimento aumentem.

Diante desse cenário, o KDD auxilia na obtenção de novos conhecimentos, e auxilia a tomada de decisões, para que gestores de pessoas tomem ações que visam melhorar o engajamento dos seus colaboradores.

\section{SOLUĈ̃̃ PROPOSTA}

Nesta pesquisa objetivou-se aplicar técnicas de Mineração de Dados (MD) junto as etapas do processo de Knowledge Discovery in Database (KDD) a fim de identificar padrões e extrair conhecimentos a partir da base de dados de um software de gestão de pessoas. A base de dados fornecida, contém dados referentes a 59 empresas brasileiras de diferentes áreas de atuação. A utilização do KDD, permite identificar as principais características pessoais e organizacionais de alto impacto no engajamento dos colaboradores, gerando novos conhecimentos aos especialistas do negócio.

\section{PROJETO}

O desenvolvimento desse projeto, foi auxiliado pelos especialistas de negócios, que ofereceram suporte e conhecimentos relacionados a área de gestão de pessoas.

A base de dados do software de gestão de pessoas foi disponibilizada, possibilitando a consulta dos dados relacionados as características das organizações, características dos colaboradores e também respostas de perguntas relacionadas ao clima e engajamento do colaborador.

Foi realizada uma pesquisa exploratória que foi fundamental para o melhor entendimento dos dados, permitindo visualizar ruídos e outliers nos registros armazenados, e também gerar informações prévias sobre o engajamento dos colaboradores.

A etapa do pré-processamento foi realizada, sendo aplicadas as tarefas de limpeza, transformação e seleção de dados. A base de dados final possui registros referentes a 4652 colaboradores, com informações referentes as características dos colaboradores (sexo, idade, cargo, nível escolar, etc.), a características das organizações (unidade federativa, área de atuação, porte, etc.) e a dados relacionados a opinião dos colaboradores (bem-estar, felicidade, inovação, motivação, engajamento, etc.).

$\mathrm{Na}$ etapa de MD, foi selecionada a técnica de agrupamento utilizando o algoritmo K-means para auxiliar no entendimento dos dados, agrupando registros com características em comum. Para geração das regras de associação, foi utilizado o algoritmo APRIORI, pois colabora para identificar atributos que 
frequentemente estão relacionados. Para a técnica de classificação foram utilizados os algoritmos de Rede Neural Perceptron de Multiplas Camadas e Árvore de Decisão, pois possibilitam a categorização dos registros, sendo possível gerar regras e identificar atributos que mais impactam no engajamento do colaborador [4][5]

\section{CONSIDERAÇÕES FINAIS}

A partir dos dados quantitativos contínuos foi calculado o coeficiente de correlação para cada atributo, relacionando-os com o atributo de engajamento do colaborador.

Os atributos que obtiveram os maiores valores de coeficiente de correlação, foram o atributo "Me Inspira" com o coeficiente de 0.87, o atributo "Não Pediria Demissão" com o coeficiente de 0.85 e o atributo "Me Motiva" com o coeficiente de 0.84. É perceptível que o engajamento, está altamente correlacionado com a inspiração que a empresa oferece, a vontade de permanecer na atual organização e a motivação de ir trabalhar.

Em seguida foi aplicado o algoritmo K-means que gerou 4 grupos. A Tabela 1 demonstra os resultados obtidos.

Tabela 1: Grupos resultantes do K-means.

\begin{tabular}{|c|c|c|c|c|}
\hline Atributo & G1 & G2 & G3 & G4 \\
\hline Engajamento & $\mathrm{N}$ & $\mathrm{AE}$ & $\mathrm{D}$ & $\mathrm{E}$ \\
\hline UF & RJ & $\mathrm{SC}$ & $\mathrm{SC}$ & $\mathrm{SC}$ \\
\hline Área & Tecno & Tecno. & Tecno. & Tecno. \\
\hline Ótima instituição & Boa & Não info. & Péssima & Ótima \\
\hline $\begin{array}{l}\text { Orgulho } \\
\text { instituição }\end{array}$ & Alto & Não info. & $\begin{array}{l}\text { Muito } \\
\text { Baixo }\end{array}$ & $\begin{array}{l}\text { Muito } \\
\text { Alto }\end{array}$ \\
\hline Pediria demissão & $\begin{array}{l}\text { Muito } \\
\text { Alto }\end{array}$ & Não info. & $\begin{array}{l}\text { Muito } \\
\text { Alto }\end{array}$ & Neutro \\
\hline Penso em sair & Neutro & Não info. & $\begin{array}{l}\text { Muito } \\
\text { Alto }\end{array}$ & Baixo \\
\hline Me inspira & Neutro & $\begin{array}{l}\text { Muito } \\
\text { Alto }\end{array}$ & $\begin{array}{l}\text { Muito } \\
\text { Baixo }\end{array}$ & Alto \\
\hline Me motiva & Neutra & $\begin{array}{l}\text { Muito } \\
\text { Alto }\end{array}$ & $\begin{array}{l}\text { Muito } \\
\text { Baixo }\end{array}$ & $\begin{array}{l}\text { Muito } \\
\text { Alto }\end{array}$ \\
\hline Inovação & Neutra & Alto & Baixo & Neutra \\
\hline Felicidade & Neutra & Alto & Neutra & Alta \\
\hline Bem-estar & Neutra & Alto & Neutra & Alta \\
\hline Desenvolvimento & Neutra & Alto & Neutra & Alto \\
\hline Estrutura & Neutra & Alto & Neutra & Alto \\
\hline Carreira & Neutra & Alto & Neutra & Alto \\
\hline Feedback & Neutra & Alto & Neutra & Alto \\
\hline Relacionamento & Neutra & Alto & Neutra & Alto \\
\hline Alinhamento & Neutra & Alto & Neutra & Alto \\
\hline Liderança & Neutra & Alto & Neutra & Alto \\
\hline Embaixadorismo & Neutra & Alto & Neutra & Alto \\
\hline
\end{tabular}

\begin{tabular}{l}
\hline Justiça Neutra Alto $\quad$ Baixo $\quad$ Neutra \\
\hline Os grupos foram divididos de forma que cada nível de engajamento \\
(Altamente Engajado, Engajado, Neutro e Desengajado) estivesse \\
em grupos diferentes.
\end{tabular}

Em sequência, foi aplicado o algoritmo de Árvore de Decisão J48, utilizando o teste de validação cruzada com 10 folds, obteve-se uma acurácia de 90,037\% e o F-measure de 0,90. Utilizando o algoritmo de Redes Neurais Perceptron Multicamadas, com teste de validação cruzada com 10 folds, obteve-se uma acurácia de 93,1\% e o Fmeasure de 0,93 . A partir do modelo de rede neural foi possível extrair os atributos que mais impactam no engajamento do colaborador. A Figura 1 demonstra os resultados encontrados.

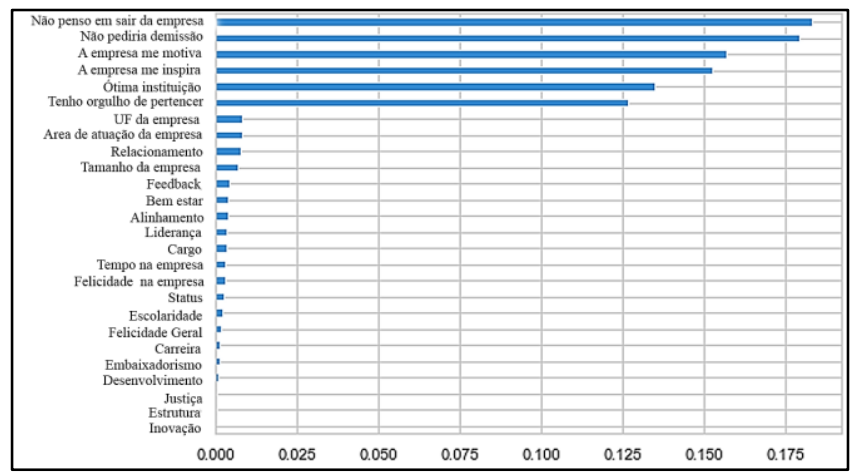

Figura 1: Atributos extraídos da Rede Neural que mais impactam no engajamento do colaborador.

Para a rede neural, os atributos que mais impactam no engajamento do colaborador, são o "Não Pediria Demissão" e o "Não Penso em Sair".

Por fim foi aplicado o algoritmo APRIORI utilizando como parâmetro a confiança de 0.90. 254 regras foram geradas, das quais as que mais se destacaram foram:

1. Se "Ótima instituição" = Péssima, então Desengajado. Confiança de 0.97;

2. Se "Felicidade" = Alta e "Me Motiva" = Muito Alta e "Não penso em sair" = Não Respondido, então Altamente Engajado. Confiança de 0.96;

Embora os resultados apresentados ainda não tenham sido validados pelos especialistas, é possível identificar que os algoritmos encontraram padrões nos registros selecionados, gerando novos conhecimentos. Caso esses conhecimentos sejam validados, será possível utiliza-los para tomar decisões futuras com o objetivo de melhorar o engajamento dos colaboradores.

\section{REFERENCIAS}

[1] Idalberto Chiavenato. Gestão de pessoas: o novo papel dos recursos humanos nas organizações. 3. ed. Rio de Janeiro: Elsevier, 2008.

[2] Simon Albrecht, . Handbook of Employee Engagement: Perspectives, Issues, Research and Practice. Cheltenham, UK: Edward Elgar Publishing, 2010.

[3] Anitha Jagannathan. Determinants of employee engagement and their impact on employee performance. International journal of productivity and performance management, v. 63 , n. 3, p. 308, 2014. 
XI Computer on the Beach

2 a 4 de Setembro de 2020, Baln. Camboriú, SC, Brasil

Favarin and Martins

[4] Usama Fayyad, Gregory Piatetsky-Shapiro and Padhraic Smyth. From Data Mining to Knowledge Discovery in Databases. American Association for Artificial Intelligence, 1996.

[5] Vipin Kumar, Michael Steinbach, and Pang-Ning Tan. Introdução ao Data Mining Mineração de Dados. Rio de Janeiro: Ciência Moderna, 2009. 